\title{
Identification of GNA12-driven gene signatures and key signaling networks in ovarian cancer
}

\author{
JI-HEE HA ${ }^{1,2^{*}}$, MURALIDHARAN JAYARAMAN ${ }^{1,2^{*}}$, MINGDA YAN $^{1 *}$, PADMAJA DHANASEKARAN ${ }^{1}$, \\ CIRO ISIDORO $^{3}$, YONG-SANG SONG ${ }^{4}$ and DANNY N. DHANASEKARAN ${ }^{1,2}$ \\ ${ }^{1}$ Stephenson Cancer Center, The University of Oklahoma Health Sciences Center; \\ ${ }^{2}$ Department of Cell Biology, The University of Oklahoma Health Sciences Center, Oklahoma, OK 73104, USA; \\ ${ }^{3}$ Laboratory of Molecular Pathology and NanoBioImaging, Department of Health Sciences, University of \\ Eastern Piedmont, I-17-28100 Novara, Italy; ${ }^{4}$ Department of Obstetrics and Gynecology, Cancer Research \\ Institute, College of Medicine, Seoul National University, Seoul 151-921, Republic of Korea
}

Received April 20, 2021; Accepted July 16, 2021

DOI: $10.3892 / \mathrm{ol} .2021 .12980$

\begin{abstract}
With the focus on defining the oncogenic network stimulated by lysophosphatidic acid (LPA) in ovarian cancer, the present study sought to interrogate the oncotranscriptome regulated by the LPA-mediated signaling pathway. LPA, LPA-receptor (LPAR) and LPAR-activated $\mathrm{G}$ protein $12 \alpha$-subunit, encoded by $\mathrm{G}$ protein subunit $\alpha 12$ (GNA12), all serve an important role in ovarian cancer progression. While the general signaling mechanism regulated by LPA/LPAR/GNA12 has previously been characterized, the global transcriptomic network regulated by GNA12 in ovarian cancer pathophysiology remains largely unknown. To define the LPA/LPAR/GNA12-orchestrated oncogenic networks in ovarian cancer, transcriptomic and bioinformatical analyses were conducted using SKOV3 cells, in which the expression of GNA12 was silenced. Array analysis was performed in Agilent SurePrint G3 Human Comparative Genomic Hybridization 8x60 microarray platform. The array results were validated using Kuramochi cells. Gene and functional enrichment analyses were performed using Database for Annotation, Visualization and Integrated Discovery, Search Tool for Retrieval of Interacting Genes and Cytoscape algorithms. The results indicated a paradigm in
\end{abstract}

Correspondence to: Dr Danny N. Dhanasekaran, Stephenson Cancer Center, The University of Oklahoma Health Sciences Center, 975 North East 10th Street, Oklahoma, OK 73104, USA

E-mail: danny-dhanasekaran@ouhsc.edu

"Contributed equally

Abbreviations: LPA, lysophospatidic acid; LPAR, lysophosphatidic acid receptor

Key words: ovarian cancer, lysophosphatidic acid, G protein subunit $\alpha 12$, gene expression, genomics, signaling-network which GNA12 drove ovarian cancer progression by upregulating a pro-tumorigenic network with $A K T 1, V E G F A, T G F B$ 1, BCL2L1, STAT3, insulin-like growth factor 1 and growth hormone releasing hormone as critical hub and/or bottleneck nodes. Moreover, GNA12 downregulated a growth-suppressive network involving proteasome 20S subunit (PSM) $\beta 6, P S M$ a6, PSM ATPase 5, ubiquitin conjugating enzyme E2 E1, PSM non-ATPase 10, NDUFA4 mitochondrial complex-associated, NADH:ubiquinone oxidoreductase subunit B8 and anaphase promoting complex subunit 1 as hub or bottleneck nodes. In addition to providing novel insights into the LPA/LPAR/GNA12-regulated oncogenic networks in ovarian cancer, the present study identified several potential nodes in this network that could be assessed for targeted therapy.

\section{Introduction}

Ovarian cancer is the seventh most common cancer type in women worldwide, with 250,000 new cases diagnosed worldwide annually, and it lead to 185,000 deaths in 2020 (1). Recent analysis has estimated that the deaths associated with ovarian cancer would be as high as 13,770 by 2021 in the USA alone (2). The high mortality rate in ovarian cancer is associated with a late diagnosis, as well as a lack of an effective targeted therapy $(3,4)$.

The observation that lysophosphatidic acid (LPA) synthesized by cancer cells acts as an endogenous growth factor, and that LPA-mediated signaling pathways serve a tumor-promoting role across numerous cancer types, including ovarian cancer, is clinically significant $(5,6)$. LPA was initially identified as a platelet derived bioactive phospholipid that stimulated the proliferation of fibroblasts involved in wound healing (7). Subsequent studies have shown that LPA stimulates multiple signaling pathways underlying cell proliferation, migration, and survival via specific G-protein coupled receptors and the associated heterotrimeric $\mathrm{G}$ proteins $(8,9)$. Of the different $\mathrm{G}$ proteins that could be activated by LPA-receptors (LPARs), G protein 12 (G12) has been identified as the major conduit involved in LPA-mediated mitogenic signaling (10-12). In 
ovarian cancer, cancer cells synthesize and release LPA into the tumor microenvironment (TME). LPA present in the TME promotes cancer progression and metastasis via the activation of specific LPA-receptors (LPARs) that are present in multicellular components of the TME $(13,14)$. In cancer cells, LPA stimulates an autocrine signaling loop via the activation of cancer cell-bound G-protein coupled LPARs. Although $G$ protein coupled receptors, such as LPARs, have proven to be highly amenable for drug development, targeting LPARs in ovarian cancer has been challenging. High concentrations of LPA in the intraperitoneal ascites surrounding the ovarian cancer tissue and the close proximity of the LPA-synthetic machinery to LPARs on the surface of ovarian cancer cells have impeded LPAR-targeted therapeutic strategies in ovarian cancer. Recent studies from several laboratories, including ours, have reported that the $\alpha$-subunit of the oncogene G-protein G12, encoded by the gene G protein subunit $\alpha 12$ (GNA12), is the major conduit involved in transmitting oncogenic signals in numerous cancer types, including ovarian cancer (15-20). It has been revealed that either LPAR-stimulated activation or mutational activation of GNA12, referred to as the gep oncogene, induces the oncogenic proliferation of ovarian cancer cells $(15,16)$.

Tumorigenesis and tumor progression often involve the deregulation of multiple pathways, impacting a cell-wide signaling network rather than an alteration in a single gene or pathway (21). Therefore, we hypothesized that the transcriptomic analysis based on the aggregated expression of genes associated with multiple pathways co-regulated by GNA12 could provide additional insights into the LPA/LPAR/GNA12-induced oncogenic signaling network in ovarian cancer. Based on this rationale, the present study aimed to investigated GNA12-orchestrated effects in ovarian cancer pathobiology using micro-array based transcriptomic analysis. Herein, the results from pathway-based bioinformatics analyses are shown in order to define the co-regulatory signaling circuits regulated by GNA12 in ovarian cancer. Using SKOV3 cells in which GNA12 had been silenced, transcriptomic profiling was conducted to identify the differentially expressed genes (DEGs). Moreover, array results were validated by monitoring the expression levels of representative DEGs via reverse transcription-quantitative (RT-q) PCR analysis in GNA12-silenced-Kuramochi cells. Further Gene Ontology (GO) enrichment and protein-protein interaction (PPI) network analyses were performed using web-based Database for Annotation, Visualization and Integrated Discovery (DAVID) and Search Tool for Retrieval of Interacting Genes (STRING), as well as Cytoscape software applications. In addition to providing a novel insight into the organizational structure of LPA/LPAR/GNA12-driven transcriptomic network in ovarian cancer, the present study has identified specific hub and bottleneck nodes that can be targeted individually or collectively for effective targeted adjuvant therapy for ovarian cancer.

\section{Materials and methods}

Cell lines and culture. High grade serous carcinoma cell line Kuramochi and non-serous ovarian carcinoma cell line SKOV3 were obtained from American Type Culture Collection (Manassas, VA) and the cells were authenticated by short tandem repeat analysis as described (13). Kuramochi cells were maintained in Roswell Park Memorial Institute (RPMI)-1640 medium (Cellgro) and SKOV3 cells were maintained in Dulbecco's modified Eagle's medium (DMEM) (Cellgro), both at $37^{\circ} \mathrm{C}$ in a $5 \% \mathrm{CO}_{2}$ incubator. In both cases, the media were supplemented with $10 \%$ FBS (Gemini Bio-Products), $50 \mathrm{U} / \mathrm{ml}$ penicillin, $50 \mu \mathrm{g} / \mathrm{ml}$ streptomycin (Cellgro). For LPA-stimulation studies, 18.1 LPA (1-oleoyl-2-h ydroxy-sn-glycero-3-phosphate; cat. no. 85730), was obtained from Avanti Polar Lipids (Alabaster, AL). LPA was dissolved in $10 \mathrm{mM}$ stock solutions in phosphate buffered saline containing $1 \% \mathrm{BSA}$ and stored at $-80^{\circ} \mathrm{C}$ until use.

Human cell lines and methods used in this study were approved by the Institutional Review Board for the protection of the Human Subjects of the University of Oklahoma (approval no. 9599).

Transfection methods. Silencing of GNA12 in SKOV3 cells was carried out as described in our previously publication (16). Briefly, non-target scrambled control shRNA pLKO.1 vector construct (Sigma-Aldrich; Merck KGaA (SHC002) and pLKO.1 vector construct targeting GNA12/Ga12 (RHS3979-98491914; Open Biosystems) were stably transfected into SKOV3 cells using Amaxa Biosystems Nucleofector II, according to the instructions of the manufacturer. The stably transfected NS control and $\mathrm{G} \alpha$-silenced clones were selected with puromycin ( $2 \mu \mathrm{g} / \mathrm{ml}$; MP Biomedicals) and single clones were picked, expanded to obtain stable cell lines. Prior to the array analysis, the silencing of GNA12-expression was ascertained by immunoblot analysis. Silencing of GNA12 in Kuramochi cells were carried out using siRNAs targeting GNA12 (siGENOME Human GNA12 siRNA SMARTpool; cat. no. M-008435-00-0005) and non-targeting scrambled control siRNAs control (siGENOME Non-Targeting siRNA Pool; cat. no. D-001206-13-05) were obtained from Dharmacon/Horizon Discovery. Kuramochi cells were transfected with siRNA using Lipofectamine RNAiMAX reagent (Invitrogen, Life Technologies) as recommended by the manufacturer. Kuramochi cells were seeded in 6-well plates at a density of $1 \times 10^{5}$ cells per well and incubated for $24 \mathrm{~h}$. Lipofectamine RNAiMAX reagent $(9 \mu \mathrm{l})$ in $300 \mu \mathrm{l}$ of Opti-MEM (Invitrogen, Life Technologies) was incubated for $5 \mathrm{~min}$ at room temperature. siRNA was added to the Opti-MEM-lipofectamine RNAiMAX solution to a final concentration of $100 \mathrm{nM}$. The mixture was added to the cell culture, and after $48 \mathrm{~h}$ incubation for gene silencing, the cells were collected for RT-qPCR studies. Expression of GNA12 in the transfectants was monitored by RT-qPCR analysis.

Transcriptomic analysis. Transcriptome profiles were obtained using Agilent SurePrint G3 Human Comparative Genomic Hybridization 8x60 microarray platform. SKOV3-shScr (non-specific scrambled shRNA control) and SKOV3-shGNA12 cells were cultured for $24 \mathrm{~h}$, followed by $16 \mathrm{~h}$ of serum starvation. These cells were stimulated with LPA $(10 \mu \mathrm{M})$ for $16 \mathrm{~h}$ and total RNA was extracted using Qiagen RNeasy mini kit (Qiagen) following the manufacturer's protocol. Agilent QuickAmp labeling kit was used to label RNA samples with Cy3-CTP and hybridized to the array slides following the manufacturer's protocol. The hybridized 
array slides were scanned using Agilent SureScan scanner at 2 microns resolution. The spot intensity was extracted using Agilent Feature Extraction version 11.0 software. Further, gene expression analysis was carried out using Agilent GeneSpring GX version 13.0. Differentially expressed genes (DEGs), with a cut-off value of $\geq 5$-fold change compared to control cells, were used for further bioinformatic analyses.

Bioinformatics analysis. Gene ontology Enrichment analysis of the DEGs was carried out using the web-based annotation tool DAVID (https://david.ncifcrf.gov/home.jsp) (22). Protein-Protein Interaction Networks Functional Enrichment Analysis was carried out using web-based (https://string-db. org/) STRING database (23). The upregulated genes and downregulated genes were analyzed separately with the highest confidence interaction score $(0.9)$ and $<10$ degree of interaction. Significant modules in the PPI network was analyzed further using Cytoscape software application (24). The hub and bottle neck nodes of the PPI network were identified using the cytoHubba plugin in Cytoscape (25). Multiple algorithms of cytoHubba including Degree, Maximal Clique Centrality and (MCC), maximum neighbourhood component (MNC), Edge Percolated Component (EPC), EcCentricity, Closeness, Betweenness, and Clustering Coefficient were used to identify the hub nodes of the PPI networks (26). BottleNeck algorithm of cytoHubba was used to identify the bottleneck nodes of the network.

RT-qPCR analysis. Total RNA was extracted using Qiagen RNeasy kit (Qiagen) following the manufacturer's instructions. cDNA synthesis was carried out using an iScript ${ }^{\mathrm{TM}}$ cDNA Synthesis Kit (Bio-Rad). Real-time quantitative PCR (RT-qPCR) was carried out using the cDNA from the above step using appropriate primers (Table SI) and SoAdvanced Universal SYBR Green Supermix (Bio-Rad) in a BioRad CFX96 Real time PCR detection system. The raw Cq values were normalized against GAPDH, housekeeping gene.

Immunoblot analysis. Antibodies to GNA12 (sc-409), GAPDH (CB1001), peroxidase-conjugated anti-rabbit IgG (W401B) were obtained from Santa Cruz Biotechnology Inc., Abcam and Promega Corporation, respectively. Immunoblot analysis was carried out according to our previously published methods (12) and developed with a Kodak Image Station 4000 MM.

Statistics. All required statistical analyses were performed using GraphPad Prism by two-tailed unpaired Student's t-test with Welch's correction. Statistics used in bioinformatics such as P-values and False Discovery Rates were calculated using the built-in statistical programs of the respective analytical tools.

\section{Results}

Identification of DEGs. Our previous studies have shown that LPA/LPAR stimulates ovarian cancer growth and cell proliferation via the activation of GNA12, encoded by the gene GNA12 or its mutationally activated configuration known as the gep oncogene $(15,16)$. To obtain an understanding of the transcriptomic network regulated by GNA12, the expression of GNA12 was silenced in SKOV3 cells using shRNAs targeting GNA12. These cells were stimulated with LPA and the DEGs in GNA12-silenced cells compared with those in the scrambled shRNA control group were identified using an Agilent array. With a cut-off value of $\geq 5$-fold change, compared with control cells, GNA12-silenced cells had 313 downregulated genes and 293 upregulated genes (Fig. 1A and B). Of the 313 downregulated genes, 145 genes were found to be protein-encoding genes (Table SII). Similarly, among the 293 upregulated genes, 186 genes were found to be protein-encoding genes (Table SIII). Other genes were represented by either long non-coding RNAs or pseudogene transcripts (Tables SIV).

Next, the current study aimed to validate the array results in a cell lines that represent high grade ovarian serous ovarian carcinoma (HGSOC). The expression of GNA12 was silenced in Kuramochi cells, a HGSOC cell line, using specific siRNAs targeting GNA12. After determining the efficacy of GNA12 silencing in these cells (Fig. 1C), RT-qPCR analysis was conducted to validate the expression levels of the DEGs. Downregulated genes were validated by monitoring the expression levels of the representative growth-promoting genes ankyrin repeat domain 1 ( $A N K R D 1)$, bone marrow stromal cell antigen 2 (BST2) and cancer antigen 1 (CAGE1), whereas the upregulated genes were validated by monitoring the expression levels of growth-repressive representative genes, namely autophagy-related 16-like 1 (ATG16L1), spindlin family member 3 (SPIN3), thrombopoietin (THPO) and tetraspanin 16 (TSPAN16). It was found that silencing of GNA12 led to the decreased expression of ANKRD1, BST2 and $C A G E 1$ (Fig. 1D), along with the increased expression of ATG16L1, SPIN3, THPO and TSPAN16, thereby validating the array results (Fig. 1E).

GO enrichment analysis of DEGs. It should be noted that the genes downregulated after silencing of GNA12 represent the genes whose expression was induced by GNA12, whereas the upregulated genes represent the genes whose expression was repressed by GNA12 in situ. Therefore, defining the functional relationships among the downregulated as well as the upregulated DEGs could provide insights into the mechanism via which GNA12 promotes ovarian cancer progression. Since GO enrichment analysis can provide information on the functional relationship among a large set of genes, GO analysis under the three sub-ontologies, namely biological processes (GO:BP), molecular functions (GO:MF) and cellular components (GO:CC), was conducted. GO enrichment analyses of the DEGs were performed using the web-based DAVID analytical tool (22). In GO:BP, the upregulated genes were significantly enriched in BP involving 'cell adhesion', 'proliferation' and 'cell motility' (Table I). These BP were associated with the known oncogenic functions of GNA12 in oncogenic cell proliferation and migration. In $\mathrm{GO}: \mathrm{CC}, \mathrm{CC}$ including 'plasma membrane' and 'actin-based cellular projections' formed the major categories, which was consistent with the role of GNA12 in actin cytoskeletal reorganization underlying cell invasion (20). In GO:MF, the topmost enriched categories were 'macromolecular interaction', 'chromatin and nucleic acid interaction' and 'transcriptional activation' (Table I), thus 
A

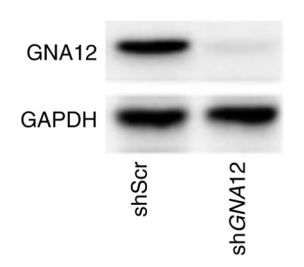

C

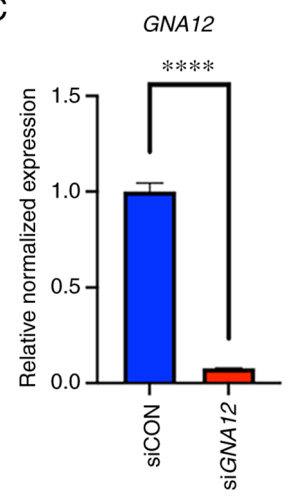

$E$

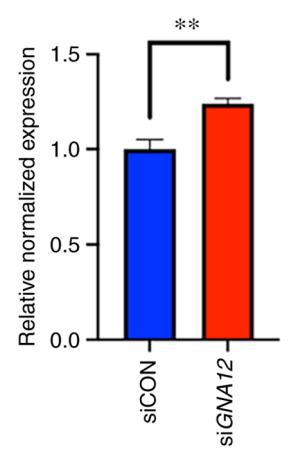

B

\begin{tabular}{|l|l|l|l|}
\hline $\begin{array}{l}\text { Silenced } \\
\text { Gene }\end{array}$ & Total DEGs & $\begin{array}{l}\text { Down- } \\
\text { regulated } \\
\text { Genes }\end{array}$ & $\begin{array}{l}\text { Up- } \\
\text { regulated } \\
\text { Genes }\end{array}$ \\
\hline GNA12 & 606 & 313 & 293 \\
\hline
\end{tabular}

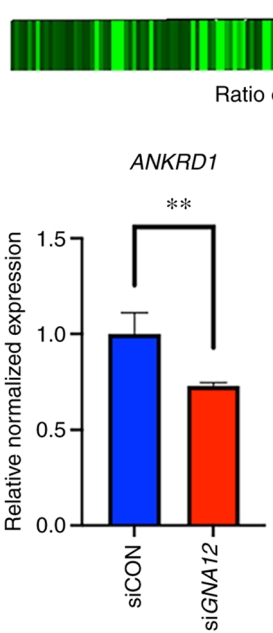

Ratio of DEGs: shGNA12 versus shScr

D

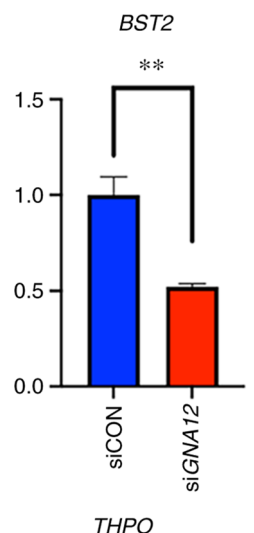

CAGE1
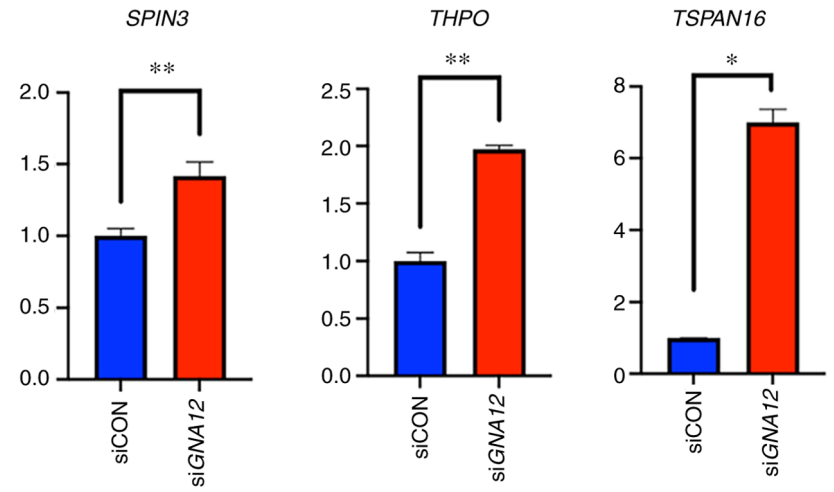

Figure 1. Heatmap of the DEGs and validation. (A) Validation of shRNA-mediated GNA12-silencing in SKOV3 cells. Expression of GNA12 was stably silenced in SKOV3 cells using shGNA12 compared with control cells stably expressing non-targeting scrambled shRNAs. (B) Heatmap of the DEGs; the ratio comparing control cells (scrambled shRNA) and GNA12-silenced cells is presented as a heat map. Red, black and green colors represent upregulated, unchanged and downregulated expression, respectively. Total number of DEGs with $>5$-fold-change compared with control values and the number of downregulated and upregulated DEGs are presented as a table. (C) Array results were validated by RT-qPCR using siRNA-mediated GNA12-silenced Kuramochi cells compared with non-targeting scrambled siRNA controls. (D) Downregulated DEGs were validated by monitoring the expression of the representative genes $A N K R D 1, B S T 2$ and $C A G E 1$ by RT-qPCR. (E) Expression of the upregulated DEEGs was validated by monitoring the expression of the representative upregulated genes ATG16L1, SPIN3, THPO, and TSPAN16 by RT-qPCR. ${ }^{*} \mathrm{P}<0.05,{ }^{* *} \mathrm{P}<0.005,{ }^{* * * *} \mathrm{P}<0.0005$. DEGs, differentially expressed genes; sh, short hairpin; GNA12, G protein subunit $\alpha$ 12; Scr, scrambled; RT-qPCR, CON, control; ANKRD1, ankyrin repeat domain 1; BST2, bone marrow stromal cell antigen 2; CAGE1, cancer antigen 1; RT-qPCR, reverse transcription-quantitative PCR; ATG16L1, autophagy-related 16-like 1; SPIN3, spindlin family member 3; THPO, thrombopoietin; TSPAN16, tetraspanin 16.

validating the role of GNA12-mediated network in molecular interactions leading to oncogenic transcriptional events.

With regards to genes that were downregulated in GNA12-silenced cells, GO:BP showed enrichment of categories associated with the overall negative regulation of cellular and BP including different aspects of 'cell death' and 'proteolytic processes' that can be linked with growth-inhibition (Table II). In GO:CC, the enriched categories included 'membrane components of the cells' and components associated with 'autophagosome membrane' and 'extracellular matrix'. This finding was in agreement with the notion that the primary site of action of GNA12 is closer to cell surface membrane (27). In GO:MF, the enriched categories were associated with 'protein binding' and peptidase functions including 'exopeptidase', 'metallopeptidase' and 'metalloexopeptidase' (Table II), which are often associated with programmed cell death (28).

Analysis of PPI networks and pathways. To further investigate the functional interactions among the proteins encoded by the DEGs, PPI network functional enrichment analysis was conducted using the STRING database (23). The upregulated and downregulated genes were analyzed separately, with the highest confidence interaction score (0.9) and $<10$ degrees of interaction. The PPI network downregulated in GNA12-silenced cells was constructed by screening 186 nodes and 306 edges (Fig. 2). The most significant module in the PPI network was determined using Cytoscape software (24). Kyoto Encyclopedia of Genes and Genomes 
Table I. GO enrichment analysis of downregulated genes in GNA12-silenced cells.

A, GO: Biological process

\begin{tabular}{llll}
\hline Term & \multicolumn{1}{c}{ Description } & Gene count & P-value \\
\hline GO:0048518 & Positive regulation of Biological Process & 45 & $6.3 \times 10^{2}$ \\
GO:0048583 & Regulation of response to Stimulus & 24 & $8.7 \times 10^{2}$ \\
GO:0007155 & Cell adhesion & 21 & $2.1 \times 10^{2}$ \\
GO:0008283 & Cell proliferation & 19 & $4.9 \times 10^{1}$ \\
GO:0048870 & Cell motility & 15 & $4.9 \times 10^{1}$ \\
\hline
\end{tabular}

B, GO: Cellular component

\begin{tabular}{llcr}
\hline Term & \multicolumn{1}{c}{ Description } & Gene count & P-value \\
\hline GO:0005886 & Plasma membrane & 45 & $6.7 \times 10^{2}$ \\
GO:0071944 & Cell periphery & 45 & $9.0 \times 10^{2}$ \\
GO:0005576 & Extracellular region & 42 & $4.8 \times 10^{2}$ \\
GO:0042995 & Cell projection & 18 & $9.3 \times 10^{2}$ \\
GO:0098862 & Cluster of actin-based cell projections & 4 & $7.8 \times 10^{2}$ \\
\hline
\end{tabular}

C, GO: Molecular function

\begin{tabular}{llrr}
\hline Term & \multicolumn{1}{c}{ Description } & Gene count & P-value \\
\hline GO:0044877 & Macromolecular complex binding & 15 & $6.0 \times 10^{2}$ \\
GO:0001067 & Regulatory region nucleic acid binding & 10 & $9.4 \times 10^{2}$ \\
GO:0000981 & Transcription factor activity & 9 & $8.5 \times 10^{2}$ \\
GO:0003982 & Chromatin binding & 8 & $5.7 \times 10^{2}$ \\
GO:0001228 & Transcriptional activator activity & 6 & $7.2 \times 10^{2}$
\end{tabular}

GO, Gene Ontology; GNA12, G protein subunit $\alpha 12$.

(KEGG) analyses indicated that the major pathways defined by GNA12-dependent genes were pathways involved in 'cancer', 'PI3K/AKT signaling', 'chemotherapy resistance' and 'FoxO signaling' (Table III). Reactome analysis expanded this further into pathways associated with signaling involving 'tyrosine kinases', 'VEGF signaling', 'PI3K/AKT signaling', 'cell surface interactions at the vascular wall', 'cancer associated aberrant signaling by PI3K' and 'signaling by receptor tyrosine kinases' (Table III).

A similar PPI network construction was performed with the genes upregulated after silencing of GNA12 by screening a total of 202 nodes and 964 edges from the STRING portal (Fig. 3). KEGG pathway analyses indicated that the network, which was repressed by GNA12, was primarily involved in 'metabolism', 'oxidative phosphorylation', 'proteasomal proteolysis', 'cell cycle arrest' and 'transcriptional misregulation in cancer' (Table IV). Reactome pathways analysis revealed that pathways regulated in this network included 'metabolism of proteins', 'cell cycle checkpoints', 'cellular stress response', 'anaphase-prophase complex (APC/C) mediated degradation of mitotic proteins' and 'ubiquitin-dependent degradation of cyclin D', all of which could be associated with growth-inhibition (Table IV).
Identification of the hub and bottleneck nodes. The network was further analyzed to identify the critical genes that define the hub nodes of the PPI network using the cytoHubba plugin in Cytoscape (25). The multiple algorithms of the cytoHubba, including Degree, MCC, MNC, EPC, EcCentricity, Closeness, Betweenness and Clustering Coefficient, were used to identify the hub nodes of the PPI networks (26). The intersecting genes identified by the different algorithms were tabulated (Table V). Results from this analysis identified AKT1, VEGFA, BCL2L1, TGFB1 and STAT3 as the top five hub nodes (Fig. 2, Insert; Table V). In addition to hub nodes, the identification of bottleneck nodes has equal or more importance in PPI networks due to their role as the key 'connector proteins' $(29,30)$. Therefore, the bottleneck nodes of the network were extracted using the BottleNeck algorithm in cytoHubba application of Cytoscape. The results demonstrated that VEGFA, AKT1 and STAT3 were defined the bottleneck nodes, in addition to IGFI and GHRH (Fig. 2, Insert).

A similar analysis was conducted to extract the hub nodes and the bottleneck nodes of the upregulated genes. The results identified proteasome 20S subunit (PSM) $\beta 6$ (PSMB6), PSM a 6 (PSMA6), PSM ATPase 5 (PSMC5), ubiquitin conjugating enzyme E2 E1 (UBE2E1) and PSM non-ATPase 10 (PSMD10), 
Table II. GO enrichment analysis of upregulated genes in GNA12-silenced cells.

A, GO: Biological process

\begin{tabular}{llll}
\hline Term & \multicolumn{1}{c}{ Description } & Gene count & P-value \\
\hline GO:0048519 & Negative regulation of biological process & 46 & $6.4 \times 10^{2}$ \\
GO:0048523 & Negative regulation of cellular process & 45 & $3.2 \times 10^{2}$ \\
GO:0006508 & Proteolysis & 20 & $7.5 \times 10^{2}$ \\
GO:0010941 & Regulation of cell death & 18 & $8.8 \times 10^{1}$ \\
GO:0042981 & Regulation of apoptotic process & 17 & $8.7 \times 10^{1}$ \\
\hline
\end{tabular}

B, GO: Cellular component

\begin{tabular}{llrr}
\hline Term & \multicolumn{1}{c}{ Description } & Gene count & P-value \\
\hline GO:0016020 & Membrane & 85 & $4.9 \times 10^{2}$ \\
GO:0071944 & Cell periphery & 51 & $5.8 \times 10^{2}$ \\
GO:0005886 & Plasma membrane & 50 & $5.9 \times 10^{2}$ \\
GO:0031012 & Extracellular matrix & 10 & $3.3 \times 10^{2}$ \\
GO:0000421 & Autophagosome membrane & $3.0 \times 10^{2}$ \\
\hline
\end{tabular}

C, GO: Molecular function

\begin{tabular}{llrr}
\hline Term & & Description & Gene count \\
\hline GO:0005488 & Binding & 122 & $9.6 \times 10^{2}$ \\
GO:0008233 & Peptidase & 10 & $9.8 \times 10^{2}$ \\
GO:0008237 & Metallopeptidase & 5 & $6.1 \times 10^{2}$ \\
GO:0008238 & Exopeptidase & 4 & $5.5 \times 10^{2}$ \\
GO:0008235 & Metalloexopeptidase & 3 & $8.9 \times 10^{2}$
\end{tabular}

GO, Gene Ontology; GNA12, G protein subunit $\alpha 12$.

the genes involved in proteasomal proteolysis, as the hub nodes (Fig. 3, Insert; Table VI). PSMA6 and PSMB6 were also identified as bottleneck nodes, along with NDUFA4 mitochondrial complex associated (NDUFA4), NADH:ubiquinone oxidoreductase subunit $\mathrm{B} 8(N D U F B 8)$ and anaphase promoting complex subunit 1 (ANAPC1) genes (Fig. 3, Insert; Table VI).

Biological significance of the hub and bottleneck nodes. The biological significance of the hub and bottleneck node genes in relation to ovarian cancer was determined via cBioPortal analysis $(31,32)$. First, the hub and bottleneck genes downregulated in GNA12-silenced cells were examined (Table V). The oncoprint profile of these genes indicated that they were either amplified or upregulated in at least $4-10 \%$ of the patients with ovarian cancer (Fig. 4). Functional annotation of these genes, as shown in Table $\mathrm{V}$, indicated that the aberrant increased expression of these genes was associated with cancer growth, progression, metastasis and therapy resistance in ovarian cancer (33-45).

Next, the hub and bottleneck genes upregulated in GNA12-silenced cells were examined (Table VI). These nodes, representing the genes that would have been suppressed by GNA12, were found to be associated with proteasome-mediated context-specific apoptotic pathways and therapy resistance in numerous cancer types (46-57). Taken together, the functional analyses of the hub and bottleneck genes indicated that the genes downregulated in GNA12-silenced cells coded for pro-tumorigenic proteins, while the genes upregulated upon silencing of GNA12 encoded anti-tumorigenic proteins (Fig. 5).

\section{Discussion}

Autocrine and paracrine signaling by LPA serve a determinant role in cancer development and progression, and this is evident in the context of ovarian cancer $(15,16)$. Our previous studies have reported that activation of GNA12 by LPA/LPAR signaling or mutational activation of GNA12 into the gep oncogene serve a critical role in the oncogenic proliferation of ovarian cancer cells $(15,16)$. In the present study, the key signaling pathways and critical genetic nodes that are aberrantly regulated by LPA/LPAR/GNA12 signaling in ovarian cancer were identified. In the cellular model used, the genes that were downregulated upon silencing of GNA12 represent the genes that would be upregulated by an intact LPA/LPAR/GNA12 signaling pathway, whereas the genes that were upregulated upon silencing 


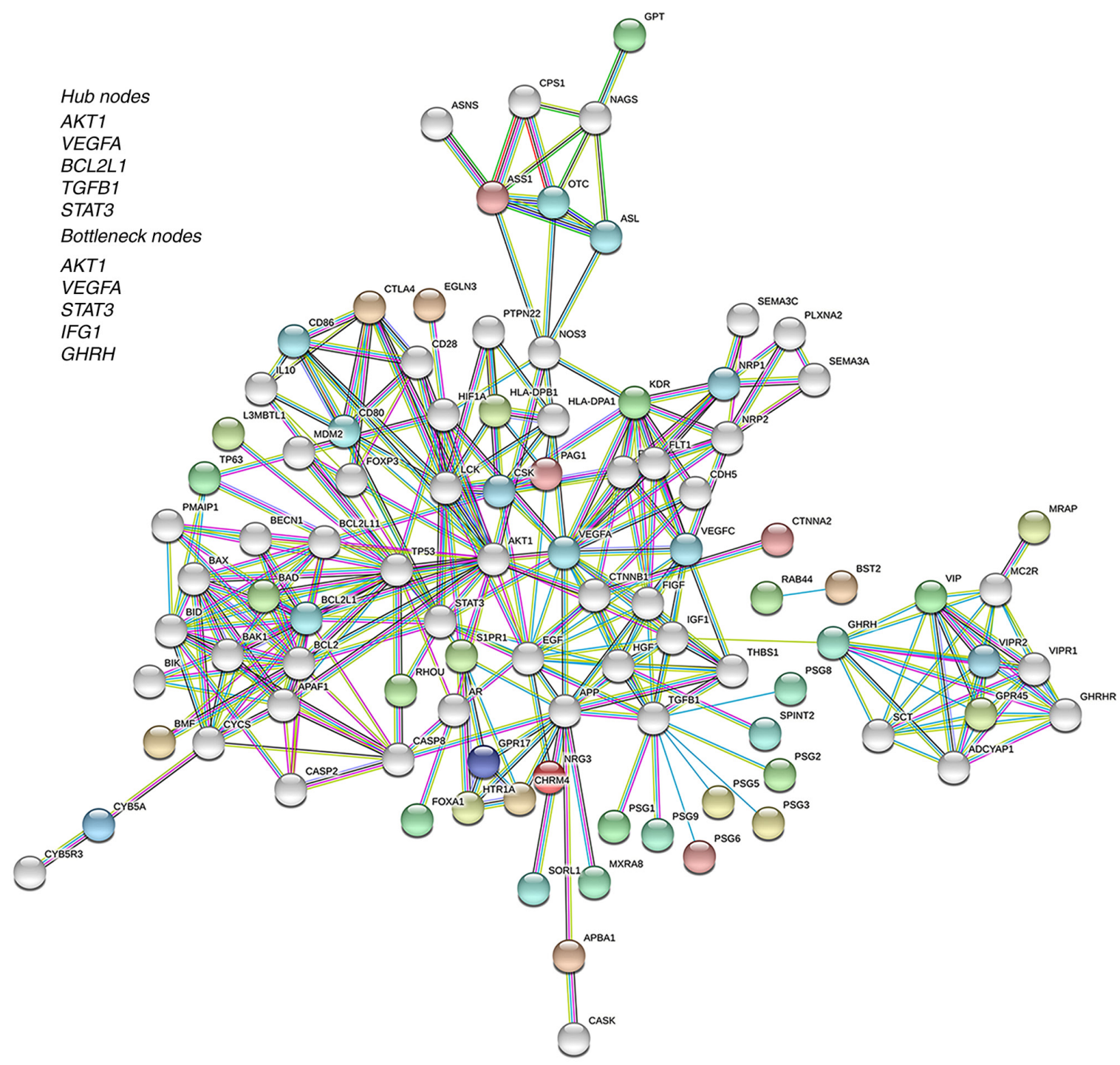

Figure 2. PPI network of downregulated genes. Using the web-based Search Tool for Retrieval of Interacting Genes tool, a PPI network of the genes downregulated in GNA12-silenced cells was constructed. Query proteins and their first shell interactions are denoted by colored nodes. Second shell interactions are in grey. Nodes of similar color identifies the specific cluster of interacting nodes. Predicted functional interactions are indicated by the connecting lines. The colors of the lines represent the types of evidence that were used to predict the PPI associations as follows: Red, known gene fusions; green, gene neighborhood; blue, gene co-occurrence; purple, experimental data; yellow, text-mining; light blue, protein homology; aqua marine, curated database; and black, co-expression. Hub and bottleneck nodes identified by the cytoHubba plugin in Cytoscape application are presented as the inset. PPI, protein-protein interaction; GNA12, G protein subunit a 12; IGF1, insulin-like growth factor 1; GHRH, growth hormone-releasing hormone.

GNA12 represent the genes that would be suppressed by this signaling pathway. The array analyses results indicated that genes that were upregulated by GNA12 (downregulated in GNA12-silenced cells) were mostly pro-tumorigenic, while genes that were downregulated by GNA12 (upregulated in GNA12-silenced cells) were growth-inhibitory. These array results were corroborated by the findings demonstrating that GNA12 silencing decreased the expression of pro-tumorigenic genes, along with a coincident increase in the expression of growth-suppressive genes. ANKRD1, BST1 and CAGE1 have been previously shown to have oncogenic role in different cancer types, including ovarian cancer. $A N K R D 1$ has been revealed to promote drug-resistance and epithelial-mesenchymal transition (EMT) in multiple cancer cells, including ovarian cancer cells $(58,59)$. Moreover, BST1 has been observed to induce EMT in ovarian cancer cells $(59,60)$, while $C A G E 1$ is known to promote both proliferation and migration in different cancer cells (61). By contrast, the genes upregulated upon silencing of GNA12, have been shown to exert a tumor suppressive role in different cancer types. For example, SPIN3 has been identified as a tumor suppressor gene that induces apoptosis in human seminoma cancer cells (62). Furthermore, ATG16L1 has been reported to be involved in promoting autophagic cell death in ovarian cancer cells (63). THPO, encoded by THPO, has also been observed to induce apoptosis in a context specific manner (64). While the cellular function of TSPAN16 remains to be fully defined, its weak expression profile in cancer cells has been considered to be indicative of its tumor suppressing potential (65). Collectively, GNA12 appears to stimulate a pro-tumorigenic network, along with the simultaneous suppression of a growth-inhibitory network.

The synergistic network organization was further clarified by the current results from the GO enrichment analyses. While GO enrichment in CC was in accordance with the known 
Table III. Pathway analysis of downregulated genes in GNA12-silenced cells.

A, Kyoto Encyclopedia of Genes and Genomes pathway

\begin{tabular}{llcc}
\hline Term & \multicolumn{1}{c}{ Description } & Gene count & False discovery rate \\
\hline hsa05200 & Pathways in cancer & 28 & $2.43 \times 10^{11}$ \\
hsa04151 & PI3K-AKT signaling pathway & 18 & $2.34 \times 10^{7}$ \\
hsa01524 & Platinum drug resistance & 13 & $5.69 \times 10^{11}$ \\
hsa01521 & EGFR tyrosine kinase inhibitor resistance & 13 & $2.35 \times 10^{9}$ \\
hsa04068 & FoxO signaling pathway & 9 & $3.60 \times 10^{5}$ \\
\hline
\end{tabular}

B, Reactome pathway

\begin{tabular}{llcc}
\hline Term & \multicolumn{1}{c}{ Description } & Gene count & False discovery rate \\
\hline HSA-9006934 & Signaling by receptor tyrosine kinases & 24 & $1.29 \times 10^{9}$ \\
HSA-194138 & Signaling by VEGF & 12 & $7.95 \times 10^{8}$ \\
HSA-2219528 & PI3K/AKT signaling in cancer & 10 & $9.32 \times 10^{7}$ \\
HSA-202733 & Cell surface interactions at the vascular wall & 9 & $1.70 \times 10^{4}$ \\
HSA-2219530 & Constitutive signaling by aberrant PI3K in cancer & 7 & $7.17 \times 10^{5}$ \\
\hline
\end{tabular}

GNA12, G protein subunit $\alpha 12$.

Table IV. Pathway analysis of upregulated genes in GNA12-silenced cells.

A, Kyoto Encyclopedia of Genes and Genomes pathway

\begin{tabular}{llcc}
\hline Term & \multicolumn{1}{c}{ Description } & Gene count & False discovery rate \\
\hline hsa-0110 & Metabolic pathways & 34 & $5.57 \times 10^{6}$ \\
hsa00190 & Oxidative phosphorylation & 26 & $1.79 \times 10^{22}$ \\
hsa03050 & Proteasome & 24 & $5.40 \times 10^{29}$ \\
hsa04218 & Cell cycle & 12 & $2.25 \times 10^{5}$ \\
hsa05202 & Transcriptional misregulation in cancer & 7 & $2.32 \times 10^{4}$ \\
\hline
\end{tabular}

B, Reactome pathway

\begin{tabular}{|c|c|c|c|}
\hline Term & Description & Gene count & False discovery rate \\
\hline HSA-392499 & Metabolism of proteins & 40 & $7.46 \times 10^{5}$ \\
\hline HSA-69620 & Cell cycle checkpoints & 33 & $6.55 \times 10^{24}$ \\
\hline HSA-5668541 & Cellular responses to stress & 35 & $2.69 \times 10^{21}$ \\
\hline HSA-174178 & $\begin{array}{l}\text { APC/C:Cdh1 mediated degradation of Cdc } 20 \text { and other } \\
\text { APC/C:Cdh1 targeted proteins in late/early mitosis }\end{array}$ & 30 & $8.83 \times 10^{35}$ \\
\hline HSA-75815 & Ubiquitin mediated degradation of cyclin D & 27 & $2.49 \times 10^{33}$ \\
\hline
\end{tabular}

APC/C, anaphase-promoting complex; Cdh, CDC20 homolog; GNA12, G protein subunit $\alpha 12$.

role of GNA12 in transmitting the plasma membrane-located LPA/LPAR signaling from the cell periphery, novel insights could be gained via the analyses of GO BP and MF. The GO:BP enrichment indicated that the pathways upregulated by GNA12, thus downregulated in GNA12-silenced cells, were associated with critical BP and MF associated with cancer progression, metastasis and therapy resistance. In fact, GO:BP, such as 'positive regulation of biological process' (GO:0048518), has already been shown to be associated with chemoresistance in HGSOC (55). Other GO:BPs, such as 'cellular response to stimulus' (GO:0048583), 'cell adhesion' (GO:0007155), ‘cell proliferation' (GO:0008283) and ‘cell 


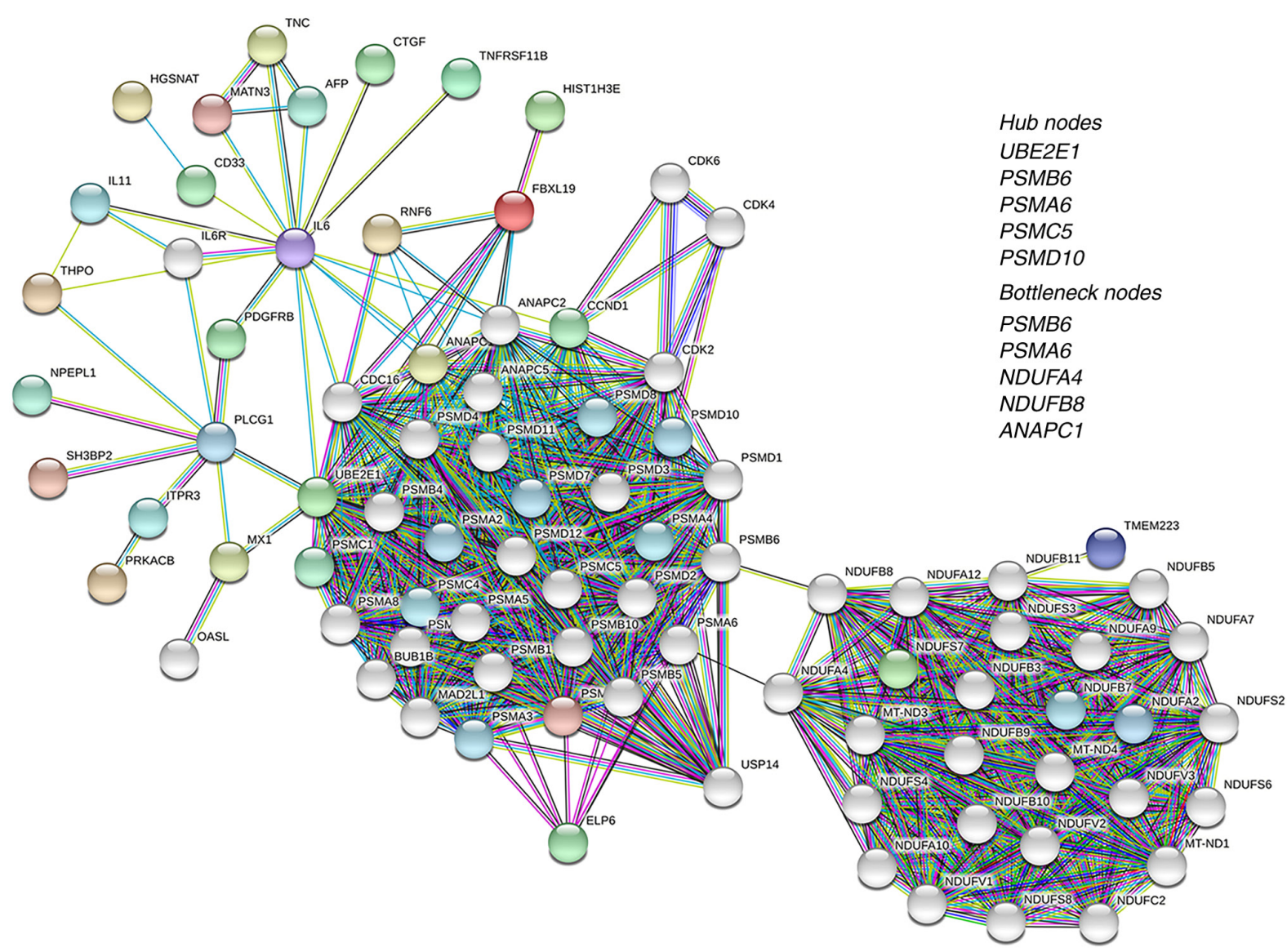

Figure 3. PPI network of upregulated genes. A PPI network of the genes upregulated in GNA12-silenced cells is presented. Colored nodes represent the query proteins and first shell interaction and white nodes denote second shell interactions. Nodes of similar color identifies the specific cluster of interacting nodes. Predicted functional interactions are indicated by the connecting lines. The colors of the lines represent the types of evidence that were used to predict the PPI associations as follows: Red, known gene fusions; green, gene neighborhood; blue, gene co-occurrence; purple, experimental data; yellow, text-mining; light blue, protein homology; aqua marine, curated database; and black, co-expression. Hub and bottleneck nodes of the PPI network derived from the use of cytoHubba plugin in Cytoscape application are presented as the inset. PPI, protein-protein interaction; GNA12, G protein subunit $\alpha$ 12; UBE2E1, ubiquitin conjugating enzyme E2 E1; PSM, proteasome 20S subunit; NDUFA4, NDUFA4 mitochondrial complex-associated; NDUFB8, NADH:ubiquinone oxidoreductase subunit B8; ANAPC1, anaphase promoting complex subunit 1 .

motility' (GO:0048870), have been associated with cancer growth, recurrence and therapy resistance in numerous cancer types $(56,57,66,67)$. Together with the indicated functions in GO:MF enrichments, the current novel findings emphasize the oncogenic role of GNA12 in transmitting signals from the LPA/LPAR signaling pathway located in the cellular periphery to a set of highly consequential nuclear events. Another significant analytical suggestion from the results was that genes suppressed by GNA12, as evidenced by their upregulation in GNA12-silenced cells, show GO enrichments in $\mathrm{BP}$ and MF associated with 'negative regulation of cell growth processes'. The GO:MF enrichment also suggested the potential role of GNA12 in suppressing proteolysis associated with negative cell proliferative.

Ovarian cancer is characterized by a heterogeneous histopathology with the manifestation of dissimilar genetic and pathway alterations. Major pathways that are aberrantly altered in a range of subtypes include TP53 $(68,69)$, PI3K/AKT (70-72), VEGF $(73,74)$, EGFR $(75,76)$ and FoxO signaling (77). It was significant that KEGG and Reactome pathway analyses of the DEGs upregulated in GNA12-silenced cells directly linked GNA12 to these multiple tumor-promoting pathways. KEGG and Reactome pathways upregulated in GNA12-silenced cells involved pathways associated with cell cycle check points, including 'APC/C mediated proteasomal degradation of mitotic proteins'. Thus, the pathway analyses present an oncogenic paradigm orchestrated by GNA12 in which mutational or LPA/LPAR activation of GNA12 leads to the stimulation of a pro-tumorigenic network, while concurrently suppressing an anti-tumorigenic network involving anti-mitotic, anti-proliferative and cellular stress pathways. This was further substantiated by the analysis of the hub and bottleneck signaling nodes derived from the PPI networks of the DEGs, especially the ones that were downregulated in GNA12-silenced cells. In line with the oncogenic role of GNA12, these genes were upregulated in distinct subsets of patients with ovarian cancer and were critically involved in ovarian cancer pathobiology. AKT1 gene is frequently upregulated in ovarian cancer and is associated with paclitaxel resistance in patients with ovarian cancer (33). Furthermore, the upregulation of VEGFA has been shown to be associated with distant metastasis and resistance to chemotherapy in patients with ovarian cancer (34-36). Increased expression of TGB1 has been correlated with EMT, tumor growth and metastasis in ovarian cancer $(37,38)$, while overexpression of $B C L 2 L 1$ is associated with anti-apoptosis effects and 
Table V. Hub and bottleneck genes downregulated in GNA12-silenced cells.

\begin{tabular}{|c|c|c|c|}
\hline Genes & Nodes & Function & (Refs.) \\
\hline$A K T$ & Hub and bottleneck & Amplified in ovarian cancer patients; confers resistance to paclitaxel. & $(33)$ \\
\hline$V E G F A$ & Hub and bottleneck & $\begin{array}{l}\text { Overexpression in ovarian cancer patients; tumor angiogenesis, associated with } \\
\text { distant metastasis and resistance to chemotherapy. }\end{array}$ & $(34-36)$ \\
\hline STAT3 & Hub and bottleneck & Tumor cell growth; survival, growth, stemness and tumor angiogenesis. & $(41)$ \\
\hline$B C L 2 L 1$ & Hub & Anti-apoptosis; confers platinum resistance. & $(39,40)$ \\
\hline$T G F B 1$ & Hub & Tumor growth, epithelial-mesenchymal transition and metastasis. & $(37,38)$ \\
\hline$I G F 1$ & Bottleneck & Overexpressed in ovarian cancer; tumor cell proliferation; immunosuppressive role. & $(42,43)$ \\
\hline GHRH & Bottleneck & $\begin{array}{l}\text { Endogenous synthesis in ovarian cancer cells; ovarian cancer growth; tumor } \\
\text { vascularization. }\end{array}$ & $(44,45)$ \\
\hline
\end{tabular}

GNA12, G protein subunit $\alpha$ 12; IGF1, insulin-like growth factor 1; GHRH, growth hormone-releasing hormone.

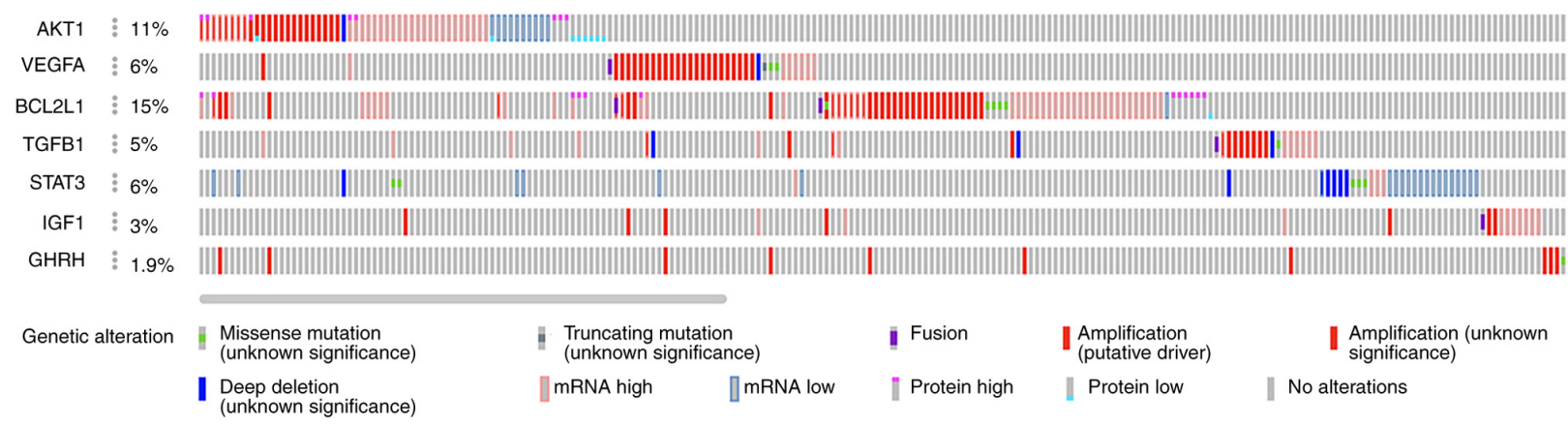

Figure 4. Genomic and expression profile of hub and bottleneck genes in patients with ovarian cancer. Genomic and expression profile of the hub and bottleneck genes in ovarian cancer patients were visualized in OncoPrint at cBioPortal web-portal. IGF1, insulin-like growth factor 1; GHRH, growth hormone-releasing hormone.

platinum resistance $(39,40)$. In addition, STAT3 signaling in ovarian cancer has been reported to be associated with tumor cell proliferation, survival, stemness and angiogenesis (41), while the overexpression of IGFI has been revealed to stimulate the proliferation of ovarian cancer cells, along with its immunosuppressive role in ovarian cancer $(42,43)$. In a similar manner, $G H R H$, which is endogenously produced in ovarian cancer cells, is involved in ovarian cancer growth and tumor vascularization $(44,45)$. The oncogenic role for these genes has also been shown by the oncoprint profiles of these genes generated using the CBioPortal. In fact, in silico data-mining indicated that all of the GNA12-regulated hub and bottleneck nodes identified her such as AKT, VEGFA, BCL2L1, TGFb1, I $G F 1$, and $G H R H$ are associated with poor prognosis in ovarian cancer (78-83).

A new paradigm emerging from the current analysis showed the potential role of GNA12 in suppressing the proteasome pathway. It is of interest to note that the proteasomal proteolytic machinery has been reported to be required for the rapid onset of death receptor-induced apoptosis in a context-specific manner $(47,48)$. In fact, it has been documented that the overexpression of PSMA6 and PSMC5 was associated with chemoresistance in prostate cancer and radiation-therapy resistance in lung cancer, respectively $(49,50)$. Moreover, ANAPC1, a hub/pathway gene in this network, is part of the $\mathrm{APC} / \mathrm{C}$, which is involved in cell cycle arrest at $\mathrm{G}_{1}$ phase. APC/C is an E3-ubiquitin ligase that regulates cell cycle arrest by marking cell cycle proteins, such as cyclins, for degradation by proteasomes during cell cycle exit $(53,54)$. UBE2E1, which was identified here as the hub and pathway gene, encodes an E2-ubiquitin conjugating enzyme. It has been revealed that UBE2E1 can complex with polycomb repressive complex 1 (PRC1), the E3 ligase complex responsible for histone $\mathrm{H} 2 \mathrm{~A}$ ubiquitination and gene silencing (46). With the established role of PRC1 complex in the silencing of tumor suppressor genes (84), it can be considered that $U B E 2 E 1$ serves an active role in PRC1-mediated silencing of tumor suppressor genes.

One of the hallmarks of cancer involves metabolic reprogramming in cancer cells, with a shift towards aerobic glycolysis. It is known that along with the glycolytic shift, cancer cells concomitantly suppress mitochondrial oxidative phosphorylation (85). While the mechanism via which cancer cells proactively resort to glycolytic shift is beginning to be understood, the role of an active signaling mechanism involved in suppressing oxidative phosphorylation has thus far remained uncharacterized. In this regard, NDUFA4 and $N D U F B 8$, which have been identified as bottleneck genes in the GNA12-suppressed network, are highly relevant. NDUFA4 and NDUFB8 are subunits of complex IV and complex I of the mitochondrial electron transport chain, and are essential components involved in mitochondrial oxidative phosphorylation (86-88). The decreased expression of NDUFA4 has been correlated with the suppression of oxidative phosphorylation and stimulation of glycolysis in renal 
Table VI. Hub and bottleneck genes upregulated in GNA12-silenced cells.

\begin{tabular}{|c|c|c|c|}
\hline Genes & Nodes & Function & (Refs.) \\
\hline PSMB6 & Hub and bottleneck & 20S proteasome subunit; context specific apoptosis. & $(47,48)$ \\
\hline PSMA6 & Hub and bottleneck & 20 S proteasome subunit; context specific apoptosis; confers chemosensitivity. & (49) \\
\hline PSMC5 & Hub & $26 \mathrm{~S}$ proteasome regulatory subunit; confers radiosensitivity. & $(50)$ \\
\hline PSMD10 & Hub & $\begin{array}{l}26 \mathrm{~S} \text { proteasome regulatory subunit; oncogene, but involved in context specific } \\
\text { apoptosis. }\end{array}$ & $(47,48)$ \\
\hline$U B E 2 E 1$ & Hub & PRC1 mediated gene silencing. & $(46)$ \\
\hline NDUFA4 & Bottleneck & $\begin{array}{l}\text { Subunit of complex IV of the mitochondrial electron transport chain; reduced } \\
\text { expression associated with metabolic reprograming in renal cell carcinoma. }\end{array}$ & $(84)$ \\
\hline NDUFB 8 & Bottleneck & $\begin{array}{l}\text { Accessory subunit of NADH dehydrogenase complex I of the mitochondrial } \\
\text { electron transport chain; reduced expression associated with metabolic } \\
\text { reprograming in breast cancer cells. }\end{array}$ & $(91)$ \\
\hline$A N A P C 1$ & Bottleneck & Cell cycle arrest; mitotic checkpoint regulator. & $(53,54)$ \\
\hline
\end{tabular}

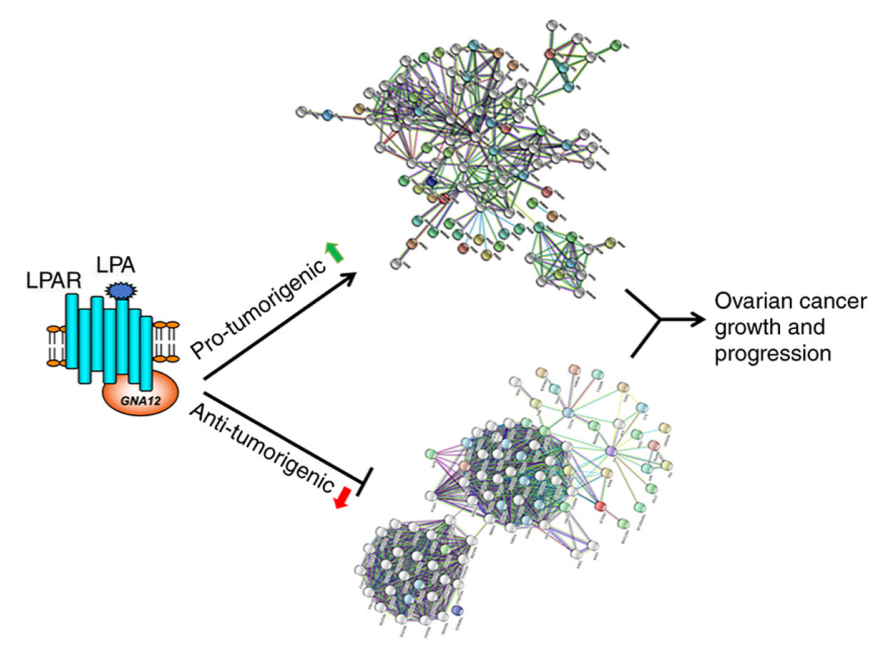

Figure 5. Schematic representation of GNA12-driven genetic networks in ovarian cancer. LPA-LPAR-stimulation or mutational activation of GNA12 drove the coordinated regulation of two genetic networks. GNA12 activated a pro-growth genetic network with the genetic nodes involved in cell proliferation and simultaneously downregulated a growth-suppressive network defined by pro-apoptotic and growth-suppressive genes. Sinergy between these networks promoted aggressive growth and progression of ovarian cancer. LPA, lysophosphatidic acid; LPAR, lysophosphatidic acid receptor; GNA12, G protein subunit $\alpha 12$.

cell carcinoma $(89,90)$. Similarly, low expression of NDUFB8 has been associated with impaired oxidative phosphorylation, along with a shift towards aerobic glycolysis in breast cancer cells (91). These findings, along with the current results that NDUFA4 and NDUFB8 were identified as bottleneck nodes, revealed the previously uncharacterized signaling node via which the LPA/LPAR/GNA12 signaling network could suppress oxidative phosphorylation to promote glycolytic shift in ovarian cancer cells. Thus, taken together, GNA12 appears to promote ovarian cell proliferation by suppressing multi-faceted anti-tumorigenic signaling nodes.
In summary, the present results provided novel insights into the mechanism via which GNA12, stimulated by LPA/LPAR or mutational activation, could coordinate the upregulation of a growth promoting signaling network, while simultaneously regulating the downregulation of a growth-suppressive signaling network, to promote ovarian cancer growth. While the dysregulation of numerous different pathways is known in ovarian cancer, the core signal processing unit that connects the signaling nodes into a coordinated oncogenic network remains unknown. The current study demonstrated such a role for the LPA/LPAR/GNA12 signaling unit in ovarian cancer. The present study identified the duplex signaling mode of GNA12 via which the pro-tumorigenic signaling network was upregulated, along with the simultaneous downregulation of growth-suppressive signaling network in ovarian cancer. It has been realized that the therapeutic targeting of a single pathway may not be an effective treatment strategy for multiple type of cancer. This is especially true in the case of ovarian cancer, due to its subtype and pathway heterogeneity. In this context, the current finding that the LPA/LPAR/GNA12 signaling nexus regulated multiple hub and bottleneck nodes of an extensive oncogenic network suggested that this axis may be a potential target for the development of network-targeted combination therapeutic strategies for treating ovarian cancer.

\section{Acknowledgements}

Not applicable.

\section{Funding}

The present research was supported by a pilot grant from the Stephenson Cancer Center, The Department of Defense Ovarian Cancer Research Program Award (grant no. W81XWH-18-1-0066) and The National Institutes of Health grant (grant no. GM103639). Computational services were supported by The National Institute of General Medical 
Sciences P20 (grant no. GM103639) and The National Cancer Institute of the National Institutes of Health (grant no. P30CA225520).

\section{Availability of data and materials}

The microarray data presented in the present study are deposited at the Gene Expression Omnibus (https://www. ncbi.nlm.nih.gov/geo/; accession no. GSE173214. Oncoprint data supporting the reported results used the Ovarian Serous Cystadenocarcinoma (TCGA, Firehose Legacy) dataset available https://www.cbioportal.org.

\section{Authors' contributions}

CI, YSS, JHH, MJ and DND conceptualized the study. MY, $\mathrm{JHH}$ and MJ developed the methodology. JHH and PD validated the experiments. MY, JHH and PD performed the formal analysis. DND procured resources. MY, MJ, PD and JHH curated and analyzed the data. DND wrote and prepared the original draft. DND, YSS and CI were responsible for writing, revising and editing the manuscript. DND supervised, acquired funds and was project administrator. All authors have read and approved the final version of the manuscript. DND, YSS, MJ, JHH and CI confirm the authenticity of all the raw data.

\section{Ethics approval and consent to participate}

Approved by the Institutional Review Board of the University of Oklahoma (approval no. \#9599).

\section{Patient consent for publication}

Not applicable.

\section{Competing interests}

The authors declare that they have no competing interests.

\section{References}

1. Sung H, Ferlay J, Siegel RL, Laversanne M, Soerjomataram I, Jemal A and Bray F: Global cancer statistics 2020: GLOBOCAN estimates of incidence and mortality worldwide for 36 cancers in 185 countries. CA Cancer J Clin 71: 209-249, 2021.

2. Siegel RL, Miller KD, Fuchs HE and Jemal A: Cancer Statistics, 2021. CA Cancer J Clin 71: 7-33, 2021.

3. Bast RC Jr, Lu Z, Han CY, Lu KH, Anderson KS, Drescher CW and Skates SJ: Biomarkers and strategies for early detection of ovarian cancer. Cancer Epidemiol Biomarkers Prev 29: 2504-2512, 2020.

4. Wang Q, Peng H, Qi X, Wu M and Zhao X: Targeted therapies in gynecological cancers: A comprehensive review of clinical evidence. Signal Transduct Target Ther 5: 137, 2020.

5. Mills GB and Moolenaar WH: The emerging role of lysophosphatidic acid in cancer. Nat Rev Cancer 3: 582-591, 2003.

6. Cui R, Bai H, Cao G and Zhang Z: The role of lysophosphatidic acid receptors in ovarian cancer: A minireview. Crit Rev Eukaryot Gene Expr 30: 265-272, 2020.

7. Moolenaar WH: LPA: A novel lipid mediator with diverse biological actions. Trends Cell Biol 4: 213-219, 1994.

8. Moolenaar WH, van Meeteren LA and Giepmans BN: The ins and outs of lysophosphatidic acid signaling. Bioessays 26: 870-881, 2004.
9. Noguchi K, Herr D, Mutoh T and Chun J: Lysophosphatidic acid (LPA) and its receptors. Curr Opin Pharmacol 9: 15-23, 2009.

10. Radhika V and Dhanasekaran N: Transforming G proteins. Oncogene 20: 1607-1614, 2001.

11. Goldsmith ZG and Dhanasekaran DN: G protein regulation of MAPK networks. Oncogene 26: 3122-3142, 2007.

12. Radhakrishnan R, Ha JH and Dhanasekaran DN: Mitogenic signaling by the gep oncogene involves the upregulation of S-phase kinase-associated protein 2. Genes Cancer 1: 1033-1043, 2010.

13. Ha JH, Radhakrishnan R, Jayaraman M, Yan M, Ward JD, Fung KM, Moxley K, Sood AK, Isidoro C, Mukherjee P, et al: LPA induces metabolic reprogramming in ovarian cancer via a pseudohypoxic response. Cancer Res 78: 1923-1934, 2018.

14. Radhakrishnan R, Ha JH, Jayaraman M, Liu J, Moxley KM, Isidoro C, Sood AK, Song YS and Dhanasekaran DN: Ovarian cancer cell-derived lysophosphatidic acid induces glycolytic shift and cancer-associated fibroblast-phenotype in normal and peritumoral fibroblasts. Cancer Lett 442: 464-474, 2019.

15. Goldsmith ZG, Ha JH, Jayaraman M and Dhanasekaran DN: Lysophosphatidic acid stimulates the proliferation of ovarian cancer cells via the gep proto-oncogene Galpha(12). Genes Cancer 2: 563-575, 2011.

16. Ha JH, Gomathinayagam R, Yan M, Jayaraman M, Ramesh R and Dhanasekaran DN: Determinant role for the gep oncogenes, Galpha12/13, in ovarian cancer cell proliferation and xenograft tumor growth. Genes Cancer 6: 356-364, 2015.

17. Juneja J and Casey PJ: Role of G12 proteins in oncogenesis and metastasis. Br J Pharmacol 158: 32-40, 2009.

18. Kelly P, Stemmle LN, Madden JF, Fields TA, Daaka Y and Casey PJ: A role for the G12 family of heterotrimeric G proteins in prostate cancer invasion. J Biol Chem 281: 26483-24490, 2006.

19. Kelly P, Moeller BJ, Juneja J, Booden MA, Der CJ, Daaka Y, Dewhirst MW, Fields TA and Casey PJ: The G12 family of heterotrimeric $\mathrm{G}$ proteins promotes breast cancer invasion and metastasis. Proc Natl Acad Sci USA 103: 8173-8178, 2006.

20. Liu SC, Jen YM, Jiang SS, Chang JL, Hsiung CA, Wang CH and Juang JL: G(alpha)12-mediated pathway promotes invasiveness of nasopharyngeal carcinoma by modulating actin cytoskeleton reorganization. Cancer Res 69: 6122-6130, 2009.

21. Wuchty S, Zhang A, Walling J, Ahn S, Li A, Quezado M, Oberholtzer C, Zenklusen JC and Fine HA: Gene pathways and subnetworks distinguish between major glioma subtypes and elucidate potential underlying biology. J Biomed Inform 43: 945-952, 2010.

22. Huang DW, Sherman BT, Tan Q, Kir J, Liu D, Bryant D, Guo Y, Stephens R, Baseler MW, Lane HC and Lempicki RA: DAVID Bioinformatics Resources: Expanded annotation database and novel algorithms to better extract biology from large gene lists. Nucleic Acids Res 35: W169-W175, 2007.

23. Szklarczyk D, Gable AL, Lyon D, Junge A, Wyder S, HuertaCepas J, Simonovic M, Doncheva NT, Morris JH, Bork P, et al: STRING v11: Protein-protein association networks with increased coverage, supporting functional discovery in genome-wide experimental datasets. Nucleic Acids Res 47: D607-D613, 2019.

24. Shannon P, Markiel A, Ozier O, Baliga NS, Wang JT, Ramage D, Amin N, Schwikowski B and Ideker T: Cytoscape: A software environment for integrated models of biomolecular interaction networks. Genome Res 13: 2498-2504, 2003.

25. Chin $\mathrm{CH}$, Chen $\mathrm{SH}, \mathrm{Wu} \mathrm{HH}, \mathrm{Ho} \mathrm{CW}, \mathrm{Ko} \mathrm{MT}$ and Lin CY: cytoHubba: Identifying hub objects and sub-networks from complex interactome. BMC Syst Biol 8 (Suppl 4): S11, 2014.

26. Liu Z, Meng J, Li X, Zhu F, Liu T, Wu G and Zhang L: Identification of hub genes and key pathways associated with two subtypes of diffuse large B-cell lymphoma based on gene expression profiling via integrated bioinformatics. Biomed Res Int 2018: 3574534, 2018

27. Vogler O, Barcelo JM, Ribas C and Escriba PV: Membrane interactions of $\mathrm{G}$ proteins and other related proteins. Biochim Biophys Acta 1778: 1640-10652, 2008.

28. Solary E, Eymin B, Droin N and Haugg M: Proteases, proteolysis, and apoptosis. Cell Biol Toxicol 14: 121-132, 1998.

29. Yu H, Kim PM, Sprecher E, Trifonov V and Gerstein M: The importance of bottlenecks in protein networks: Correlation with gene essentiality and expression dynamics. PLoS Comput Biol 3: e59, 2007.

30. Charitou T, Bryan K and Lynn DJ: Using biological networks to integrate, visualize and analyze genomics data. Genet Sel Evol 48: 27, 2016. 
31. Cerami E, Gao J, Dogrusoz U, Gross BE, Sumer SO, Aksoy BA Jacobsen A, Byrne CJ, Heuer ML, Larsson E, et al: The cBio cancer genomics portal: An open platform for exploring multidimensional cancer genomics data. Cancer Discov 2: 401-404, 2012.

32. Gao J, Aksoy BA, Dogrusoz U, Dresdner G, Gross B, Sumer SO, Sun Y, Jacobsen A, Sinha R, Larsson E, et al: Integrative analysis of complex cancer genomics and clinical profiles using the cBioPortal. Sci Signal 6: pl1, 2013.

33. Despierre E, Lambrechts D, Neven P, Amant F, Lambrechts S and Vergote I: The molecular genetic basis of ovarian cancer and its roadmap towards a better treatment. Gynecol Oncol 117: 358-365, 2010.

34. Guan J, Darb-Esfahani S, Richter R, Taube ET, Ruscito I, Mahner S, Woelber L, Prieske K, Concin N, Vergote I, et al: Vascular endothelial growth factor receptor 2 (VEGFR2) correlates with long-term survival in patients with advanced high-grade serous ovarian cancer (HGSOC): A study from the Tumor Bank Ovarian Cancer (TOC) Consortium. J Cancer Res Clin Oncol 145: 1063-1073, 2019.

35. Sopo M, Anttila M, Hamalainen K, Kivela A, Yla-Herttuala S, Kosma VM, Keski-Nisula L and Sallinen H: Expression profiles of VEGF-A, VEGF-D and VEGFR1 are higher in distant metastases than in matched primary high grade epithelial ovarian cancer. BMC Cancer 19: 584, 2019.

36. Li X, Hu Z, Shi H, Wang C, Lei J and Cheng Y: Inhibition of VEGFA increases the sensitivity of ovarian cancer cells to chemotherapy by suppressing VEGFA-Mediated Autophagy. Onco Targets Ther 13: 8161-8171, 2020.

37. Bai Y, Li LD, Li J, Chen RF, Yu HL, Sun HF, Wang JY and Lu X: A FXYD5/TGF//SMAD positive feedback loop drives epithelialtomesenchymal transition and promotes tumor growth and metastasis in ovarian cancer. Int J Oncol 56: 301-314, 2020.

38. Liang S, Yao Q, Wei D, Liu M, Geng F, Wang Q and Wang YS: KDM6B promotes ovarian cancer cell migration and invasion by induced transforming growth factor- $\beta 1$ expression. J Cell Biochem 120: 493-506, 2019.

39. Beale PJ, Rogers P, Boxall F, Sharp SY and Kelland LR: BCL-2 family protein expression and platinum drug resistance in ovarian carcinoma. Br J Cancer 82: 436-440, 2000.

40. Yuan J, Lan H, Jiang X, Zeng D and Xiao S: Bcl2 family: Novel insight into individualized therapy for ovarian cancer (Review) Int J Mol Med 46: 1255-1265, 2020.

41. Liang R, Chen X, Chen L, Wan F, Chen K, Sun Y and Zhu X STAT3 signaling in ovarian cancer: A potential therapeutic target. J Cancer 11: 837-848, 2020.

42. Diener A and Rohrmann S: Associations of serum carotenoid concentrations and fruit or vegetable consumption with serum insulin-like growth factor (IGF)-1 and IGF binding protein-3 concentrations in the Third National Health and Nutrition Examination survey (NHANES III). J Nutr Sci 5: e13, 2016.

43. Yahya MA, Sharon SM, Hantisteanu S, Hallak M and Bruchim I: The role of the insulin-like growth factor 1 pathway in immune tumor microenvironment and its clinical ramifications in gynecologic malignancies. Front Endocrinol (Lausanne) 9: 297, 2018

44. Khorram O, Garthwaite M, Grosen E and Golos T: Human uterine and ovarian expression of growth hormone-releasing hormone messenger RNA in benign and malignant gynecologic conditions. Fertil Steril 75: 174-179, 2001

45. Klukovits A, Schally AV, Szalontay L, Vidaurre I, Papadia A, Zarandi M, Varga JL, Block NL and Halmos G: Novel antagonists of growth hormone-releasing hormone inhibit growth and vascularization of human experimental ovarian cancers Cancer 118: 670-680, 2012.

46. Wheaton K, Sarkari F, Stanly Johns B, Davarinejad H, Egorova O, Kaustov L, Raught B, Saridakis V and Sheng Y: UbE2E1/UBCH6 is a critical in vivo E2 for the PRC1-catalyzed ubiquitination of H2A at lys-119. J Biol Chem 292: 2893-2902, 2017.

47. Sohn D, Totzke G, Schulze-Osthoff K and Janicke RU: Friend or foe? The proteasome in combined cancer therapy. Cell Cycle 5: 841-845, 2006

48. Sohn D, Totzke G, Essmann F, Schulze-Osthoff K, Levkau B and Janicke RU: The proteasome is required for rapid initiation of death receptor-induced apoptosis. Mol Cell Biol 26: 1967-1978, 2006.

49. Milone MR, Pucci B, Bifulco K, Iannelli F, Lombardi R, Ciardiello C, Bruzzese F, Carriero MV and Budillon A: Proteomic analysis of zoledronic-acid resistant prostate cancer cells unveils novel pathways characterizing an invasive phenotype. Oncotarget 6: 5324-5341, 2015.
50. Yim JH, Yun HS, Lee SJ, Baek JH, Lee CW, Song JY, Um HD, Park JK, Kim JS, Park IC and Hwang SG: Radiosensitizing effect of PSMC5, a 19S proteasome ATPase, in H460 lung cancer cells. Biochem Biophys Res Commun 469: 94-100, 2016.

51. Kim J, Yu L, Chen W, Xu Y, Wu M, Todorova D, Tang Q, Feng B, Jiang L, He J, et al: Wild-type p53 promotes cancer metabolic switch by inducing PUMA-dependent suppression of oxidative phosphorylation. Cancer Cell 35: 191-203 e8, 2019.

52. Ajeawung NF, Nguyen TTM, Lu L, Kucharski TJ, Rousseau J, Molidperee S, Atienza J, Gamache I, Jin W, Plon SE, et al: Mutations in ANAPC1, encoding a scaffold subunit of the anaphase-promoting complex, cause rothmund-thomson syndrome type 1. Am J Hum Genet 105: 625-630, 2019.

53. Ping Z, Lim R, Bashir T, Pagano $M$ and Guardavaccaro D: APC/C (Cdh1) controls the proteasome-mediated degradation of E2F3 during cell cycle exit. Cell Cycle 11: 1999-2005, 2012.

54. Kernan J, Bonacci $\mathrm{T}$ and Emanuele MJ: Who guards the guardian? Mechanisms that restrain APC/C during the cell cycle. Biochim Biophys Acta Mol Cell Res 1865: 1924-1933, 2018.

55. Wu Y, Xia L, Guo Q, Zhu J, Deng Y and Wu X: Identification of chemoresistance-associated key genes and pathways in high-grade serous ovarian cancer by bioinformatics analyses. Cancer Manag Res 12: 5213-5223, 2020.

56. Chen L, Zhang J, Li H, Niu J, Xue H, Liu B, Wang Q, Luo X, Zhang F, Zhao D and Cao S: Transcriptomic analysis reveals candidate genes for female sterility in pomegranate flowers. Front Plant Sci 8: 1430, 2017

57. Hou DL, Chen L, Liu B, Song LN and Fang T: Identification of common gene networks responsive to radiotherapy in human cancer cells. Cancer Gene Ther 21: 542-548, 2014.

58. Lei Y, Henderson BR, Emmanuel C, Harnett PR and deFazio A: Inhibition of ANKRD1 sensitizes human ovarian cancer cells to endoplasmic reticulum stress-induced apoptosis. Oncogene 34: 485-495, 2015.

59. Takahashi A, Seike M, Chiba M, Takahashi S, Nakamichi S, Matsumoto M, Takeuchi S, Minegishi Y, Noro R, Kunugi S, et al: Ankyrin repeat domain 1 overexpression is associated with common resistance to afatinib and osimertinib in EGFR-mutant lung cancer. Sci Rep 8: 14896, 2018.

60. Morone S, Lo-Buono N, Parrotta R, Giacomino A, Nacci G, Brusco A, Larionov A, Ostano P, Mello-Grand M, Chiorino G, et al: Overexpression of CD157 contributes to epithelial ovarian cancer progression by promoting mesenchymal differentiation. PLoS One 7: e43649, 2012.

61. Shim E, Shim H, Bae J, Lee H and Jeoung D: CAGE displays oncogenic potential and induces cytolytic T lymphocyte activity. Biotechnol Lett 28: 515-522, 2006.

62. Janecki DM, Sajek M, Smialek MJ, Kotecki M, Ginter-Matuszewska B, Kuczynska B, Spik A, Kolanowski T, Kitazawa R, Kurpisz M and Jaruzelska J: SPIN1 is a proto-oncogene and SPIN3 is a tumor suppressor in human seminoma. Oncotarget 9: 32466-32477, 2018.

63. Satyavarapu EM, Nath S and Mandal C: Desialylation of Atg 5 by sialidase (Neu2) enhances autophagosome formation to induce anchorage-dependent cell death in ovarian cancer cells. Cell Death Discov 7: 26, 2021.

64. Ehrenreich H, Hasselblatt M, Knerlich F, von Ahsen N, Jacob S, Sperling S, Woldt H, Vehmeyer K, Nave KA and Sirén AL: A hematopoietic growth factor, thrombopoietin, has a proapoptotic role in the brain. Proc Natl Acad Sci USA 102: 862-867, 2005.

65. Puls KL, Ni J, Liu D, Morahan G and Wright MD: The molecular characterisation of a novel tetraspanin protein, TM4-B(1). Biochim Biophys Acta 1447: 93-99, 1999.

66. Lascorz J, Chen B, Hemminki K and Forsti A: Consensus pathways implicated in prognosis of colorectal cancer identified through systematic enrichment analysis of gene expression profiling studies. PLoS One 6: e18867, 2011

67. Chang IW, Liu KW, Ragunanan M, He HL, Shiue YL and Yu SC: SERPINB5 expression: Association with CCRT response and prognostic value in rectal cancer. Int J Med Sci 15: 376-84, 2018.

68. Zhang Y, Cao L, Nguyen D and Lu H: TP53 mutations in epithelial ovarian cancer. Transl Cancer Res 5: 650-663, 2016.

69. Ren YA, Mullany LK, Liu Z, Herron AJ, Wong KK and Richards JS: Mutant p53 promotes epithelial ovarian cancer by regulating tumor differentiation, metastasis, and responsiveness to steroid hormones. Cancer Res 76: 2206-2218, 2016.

70. Cheng JQ, Godwin AK, Bellacosa A, Taguchi T, Franke TF, Hamilton TC, Tsichlis PN and Testa JR: AKT2, a putative oncogene encoding a member of a subfamily of protein-serine/threonine kinases, is amplified in human ovarian carcinomas. Proc Natl Acad Sci USA 89: 9267-9271, 1992. 
71. Altomare DA, Wang HQ, Skele KL, De Rienzo A Klein-Szanto AJ, Godwin AK and Testa JR: AKT and mTOR phosphorylation is frequently detected in ovarian cancer and can be targeted to disrupt ovarian tumor cell growth. Oncogene 23: 5853-5857, 2004.

72. Ghoneum A, and Said N: PI3K-AKT-mTOR and NFkappaB pathways in ovarian cancer: Implications for targeted therapeutics. Cancers (Basel) 11: 949, 2019.

73. Masoumi Moghaddam S, Amini A, Morris DL and Pourgholami MH: Significance of vascular endothelial growth factor in growth and peritoneal dissemination of ovarian cancer. Cancer Metastasis Rev 31: 143-162, 2012.

74. Yin X, Wang X, Shen B, Jing Y, Li Q, Cai MC, Gu Z, Yang Q, Zhang Z, Liu J, et al: A VEGF-dependent gene signature enriched in mesenchymal ovarian cancer predicts patient prognosis. Sci Rep 6: 31079, 2016.

75. Glaysher S, Bolton LM, Johnson P, Atkey N, Dyson M, Torrance $\mathrm{C}$ and Cree IA: Targeting EGFR and PI3K pathways in ovarian cancer. Br J Cancer 109: 1786-1794, 2013.

76. Wilken JA, Badri T, Cross S, Raji R, Santin AD, Schwartz P Branscum AJ, Baron AT, Sakhitab AI and Maihle NJ: EGFR/HER-targeted therapeutics in ovarian cancer. Future Med Chem 4: 447-469, 2012.

77. Han GH, Chay DB, Nam S, Cho H, Chung JY and Kim JH: Prognostic implications of forkhead box protein O1 (FOXO1) and paired box 3 (PAX3) in epithelial ovarian cancer. BMC Cancer 19: 1202, 2019.

78. Cai J, Xu L, Tang H, Yang Q, Yi X, Fang Y, Zhu Y and Wang Z The role of the PTEN/PI3K/Akt pathway on prognosis in epithelial ovarian cancer: A meta-analysis. Oncologist 19: 528-335, 2014.

79. Duncan TJ, Al-Attar A, Rolland P, Scott IV, Deen S, Liu DT, Spendlove I and Durrant LG: Vascular endothelial growth factor expression in ovarian cancer: A model for targeted use of novel therapies? Clin Cancer Res 14: 3030-3035, 2008.

80. Hu Q, Hisamatsu T, Haemmerle M, Cho MS, Pradeep S, Rupaimoole R, Rodriguez-Aguayo C, Lopez-Berestein G Wong STC, Sood AK and Afshar-Kharghan V: Role of platelet-derived Tgf $\beta 1$ in the progression of ovarian cancer. Clin Cancer Res 23: 5611-5621, 2017.

81. Bruchim I and Werner H: Targeting IGF-1 signaling pathways in gynecologic malignancies. Expert Opin Ther Targets 17: 307-320, 2013

82. Kahan Z, Arencibia JM, Csernus VJ, Groot K, Kineman RD, Robinson WR and Schally AV: Expression of growth hormone-releasing hormone (GHRH) messenger ribonucleic acid and the presence of biologically active GHRH in human breast, endometrial, and ovarian cancers. J Clin Endocrinol Metab 84: 582-589, 1999.
83. Yokoyama T, Kohn EC, Brill E and Lee JM: Apoptosis is augmented in high-grade serous ovarian cancer by the combined inhibition of Bcl-2/Bcl-xL and PARP. Int J Oncol 50: 1064-1074, 2017.

84. Wang H, Liu C, Cheng J, Liu J, Zhang L, He C, Shen WH, Jin H, $\mathrm{Xu} \mathrm{L}$ and Zhang Y: Arabidopsis flower and embryo developmental genes are repressed in seedlings by different combinations of polycomb group proteins in association with distinct sets of cis-regulatory elements. PLoS Genet 12: e1005771, 2016.

85. Diaz-Ruiz R, Rigoulet M and Devin A: The Warburg and Crabtree effects: On the origin of cancer cell energy metabolism and of yeast glucose repression. Biochim Biophys Acta 1807: 568-576, 2011.

86. Balsa E, Marco R, Perales-Clemente E, Szklarczyk R, Calvo E, Landazuri MO and Enríquez JA: NDUFA4 is a subunit of complex IV of the mammalian electron transport chain. Cell Metab 16: 378-386, 2012.

87. Guerrero-Castillo S, Baertling F, Kownatzki D, Wessels HJ, Arnold S, Brandt U and Nijtmans L: The assembly pathway of mitochondrial respiratory chain complex i. Cell Metab 25: 128-139, 2017.

88. Tang JX, Thompson K, Taylor RW, and Olahova M: Mitochondrial OXPHOS Biogenesis: Co-regulation of protein synthesis, import, and assembly pathways. Int J Mol Sci 21: 3820, 2020.

89. Deng M, Blondeau JJ, Schmidt D, Perner S, Muller SC and Ellinger J: Identification of novel differentially expressed lncRNA and mRNA transcripts in clear cell renal cell carcinoma by expression profiling. Genom Data 5: 173-175, 2015.

90. Muller FE, Braun M, Syring I, Klumper N, Schmidt D, Perner S, Hauser S, Müller SC and Ellinger J: NDUFA4 expression in clear cell renal cell carcinoma is predictive for cancer-specific survival. Am J Cancer Res 5: 2816-2822, 2015.

91. Lunetti P, Di Giacomo M, Vergara D, De Domenico S, Maffia M, Zara V, Capobianco L and Ferramosca A: Metabolic reprogramming in breast cancer results in distinct mitochondrial bioenergetics between luminal and basal subtypes. FEBS J 286: 688-709, 2019.

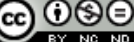

This work is licensed under a Creative Common Attribution-NonCommercial-NoDerivatives 4.0 International (CC BY-NC-ND 4.0) License. 